\title{
A BRIEF STORY OF ENGLISH MALARIA*
}

By Sir William MacArthur, K.c.B., D.s.o., M.D., F.R.C.P.

In the course of my work I have of late treated many persons suffering from recurrences of malaria contracted abroad, and some of these or their friends have had the curiosity to ask whether there is any likelihood of the disease becoming established once more in England where, in parts, mosquitoes capable of carrying malaria still abound. Doubtless the same thought has occurred to many others. The answer to the question is, "No." It is possible, of course, that a relapsing patient favourably situated might chance to infect some of the local mosquitoes, and a few cases of malaria result; but the "concentration of contagion," to use an old phrase, would fall short of the degree necessary to maintain a lasting supply of infected insects, and the imported disease accordingly would soon die out.

For centuries malaria was firmly established in certain endemic centres in England, particularly the Fen country, the marshes of the Thames Estuary, the marshes of South-East Kent, and the low-lying districts around Bridgewater. In London itself, the Lambeth and Westminster marshes were notorious. But not all the malaria that developed in London was contracted on the spot. The liability of hop-pickers to the infection-which often showed itself only in the following Springwas well known; and Defoe says that Londoners who go shooting in the Essex marshes, "often return with an Essex ague on their backs, which they find a heavier load than the fowls they have shot."

From these permanent homes, every now and again, the disease spread in epidemic form during very warm summers, especially if several such followed in succession. Since the development of parasites in the mosquito ceases when the temperature falls below $60^{\circ} \mathrm{F}$., it was only during a relatively prolonged spell of hot weather that the mass infection of insects necessary to produce an epidemic could come about. The last of these extensive epidemics occurred in 1858 and 59 , two hot summers, and preceded by that of 1857 also unusually hot. It might surprise Londoners to know that of all the patients treated at St. Thomas's Hospital during the decade I850-60, $I$ in 20 was suffering from ague, and in bad years this average figure was much exceeded. At least 30 per cent of the patients treated at Gravesend Hospital about this time were cases of ague, and it is stated that nearly every person in the district suffered to a greater or less degree.

After I860 there was a marked decline in the

\footnotetext{
* Originally published in The Fordwick, April I946, issued by the Brentford and Chiswick Public Libraries, to which acknowledgment for permission to reprint this article is duly made.
}

incidence of malaria, in part due to drainage of $\frac{\pi}{\mathbb{Q}}$ swampy land, but several other factors, too compli- $\frac{\varrho}{c}$ cated to discuss here, were also actively operative. As a result of this combination the number of news infections fell short of the number of cures, naturalo or medicinal, and a mosquito's chance of becoming successfully infected grew less and less.

The variety of malaria most prevalent in England $\widehat{\Phi}$ was that known as benign tertian- "benign" in contrast to malignant tertian of warmer climates, and "tertian" because in man the parasites take. 48 hours to mature and burst, thus causing $a \overrightarrow{\vec{H}}$ paroxysm, or ague-fit, every third day. Quartan ${ }_{\odot}^{\omega}$ malaria was also present but to a less extent: Here the parasites take 72 hours to mature, so 3 . that the paroxysm recurs every fourth day. Thein clinical symptoms are otherwise indistinguishable ${ }_{N}^{N}$ from those of the tertian variety, but the parasites $\frac{\overrightarrow{0}}{0}$ can easily be differentiated under the microscope. The paroxysm, whether tertian or quartan, is $\infty$ made up of three stages-cold shivers, high fever,을 and a sweat-and on an average lasts about8 hours. When the lady in Hudibras rejects the advances of the Puritan knight, telling him that love is fickle, first hot but soon turning cold, she $\overrightarrow{0}$ says: " 'Tis but an Ague that's reverst, Whose hôt $+\circ$ fit takes the Patient first." Butler could use this metaphor in full confidence that its point woufdo be appreciated by his readers, so familiar wass everyone in Stuart times with the successive stages? of the ague-fit. To-day a footnote would be $\frac{}{\varnothing}$ necessary to explain its significance to the ordinary English reader.

Malaria in England was not in general a killing disease, but repeated attacks were responsible for much ill-health. For example, the Registrar of Strood, Kent, reported in 1857: "An unusually윽 hot summer has operated still more to make the marshes and adjacent districts intensely unhealthy. $\frac{0}{3}$ Many deaths have been registered from intermittent. fever [malariaj directly or indirectly. The diseaseo is rarely fatal (under favourable circumstances). The chief mortality is amongst indigent and debili-음 tated persons and their families, who have fallen an easy prey to diseases of a general character in consequence of their reduced condition." N

When Defoe visited the Essex marshes in the course of his tour through the eastern counties in I722, he was told that the men bred in that dampw part of the world and seasoned to the place, do pretty well; but they always go into the uplandso for a wife, and that these lasses coming out of their native air into the fogs and damps get the? ague and seldom last above a year at most. Then the men go to the uplands again and fetch another, so that it is very frequent to meet with men that 
have had from five or six to fourteen or fifteen wives, "nay, and some more!" Clearly there was some drawing of the long bow, and it was hardly necessary for Defoe to add that he found his informant-a merry fellow who claimed to have passed a dozen and a half of wives through his hands-had "fibbed a little." None the less, Defoe says that he observed for himself this strange decay of the female sex, which is well known and easy to be inquired into. Nor is it less true that the inhabitants in these places do not hold out as in other countries, and very ancient people are seldom met with, so that take it one with another, not one-half of the inhabitants are natives of the place. On the other hand he asserts that the natives of the Fen country, especially those who are used to it, live healthy except now and then for an ague which they make light of, and there are many ancient people among them.

The word "malaria," meaning "bad air," is of Italian origin and reminds us that the disease was formerly attributed to noxious fumes arising from marshy ground. So far as is known, the first person to use the word in English was Horace Walpole in 1740 when he was living in Italy under the tutelage of Thomas Gray the poet. In one of his letters Walpole writes of "A horrid thing called the 'mal' aria,' which comes to Rome every summer and kills one." The Italian interloper became established and largely replaced the older "ague," as well as the more definitive "marshfever," though both of these names were common in several of the old aguish districts within my own memory. Originally the term "ague" meant not malaria but a continued fever, and was often applied to typhus, sometimes in the more specific form "the spotted ague." The word as it appears in Chaucer's warning: "Ye schul have a fever terciane, Or an agu," is interpreted as "malaria" by that august authority the Oxford Dictionary. I think that this is a mistake, for in medical texts even of a century later, "tertian fever" and "ague" are dealt with in different sections of the work and regarded as distinct diseases. Moreover Chaucer's wording indicates two contrasted and alternative maladies. In Shakespeare's day the older and the newer meanings of "ague" over-lapped, and usually he employs it for malaria both literally and also metaphorically as in "the ague-fit of fear." Once, however, he reverts to the older usage and applies it to typhus, a pestilence particularly associated with famine. This is when Macbeth says of the force besieging his castle: "Here let them lie, Till famine and the ague eat them up." The poet must have heard of many an army, first prostrated by famine, and then devoured by the spotted ague. "Ague" in this sense survived in Ireland until a much later date. The "Irish ague" that paralysed
Cromwell's army in Ireland in the winter of 1649 was typhus.

One peculiarity of the species of malaria that flourished in England is that in infected persons $c$ the parasites tend to lie dormant during the winter, later becoming active once more, with the result that the approach of early Spring is heralded by an outburst of relapses. The early Anglo-Saxon inhabitants of England were familiar with this feature of the disease, and so they called it the Lencten ádl, the Spring ill. Lencten, Spring, is means literally "long days," and the word, borrowed by the early Christian missionaries, survives to-day as "Lent." $A d l$ was eventually displaced by the Norse "ill," which we still use, for Norse words had a strange cuckoo-like propensity for pushing their English equivalents out of the linguistic nest. The Venerable Bede in his $\underset{N}{N}$ Ecclesiastical History, written in Latin, describes i the miraculous cure of a long-continued illness which he designates merely by the general term $\overrightarrow{0}$ febris, fever. It is most interesting to see that in the Anglo-Saxon translation of this work, attri- 5 buted to King Alfred, the translator identified $\vec{c}$ this malady, probably correctly, as malaria, and instead of employing one of the Anglo-Saxon equivalents of "fever," he boldly replaced Bede's vague word by the specific "Lencten ádl," malarip

Ague affected many historical and famous pes: sonages in a degree less or more grievous. James and Oliver Cromwell are declared by their contemporaries to have died of it. James's daughter Elizabeth, called for her beauty and charm "The $\stackrel{\varnothing}{\square}$ Queen of Hearts," the subject of the famous lyric $\overrightarrow{7}$ beginning: "You meaner beauties of the night," 을 is known to have suffered from over 30 paroxysms of the disease in succession, an affliction that must have reduced her to a sad state of debility and exhaustion. Milton suffered severely while at 3 Cambridge. Repeated attacks undermined Nel- $\dot{\circ}$ son's health in his youth. When Walter Ralegh* lay in the Tower awaiting the fatal day, malaria 8 troubled him sorely, and just before his execution $₹$ he uttered a fervent prayer that he might not be $ᄋ$ seized with an ague-fit on the scaffold, lest his enemies should proclaim that he had met his death, shivering with fear.

The role of the mosquito in transmitting malaria $\stackrel{\text { o }}{ }$ was finally proved in I900, twenty years after $N$

* Sir Walter at one time spelt his surname "Rauleygh" N and "Rauley," finally adopting the form "Ralegh" which $\sigma$ he used consistently for over 30 years. He never wrote "Raleigh" so far as is known. In the pedigree givinge ten generations of his ancestors, recorded by the Heralds $\overparen{D}$ in I620, the spelling "Rawleigh" is used for them all. \& "Raleigh" was used by Bacon in his defence of King " James, and also in the first printed account of the trial. These publications helped to popularise this form. What- $\frac{\vec{D}}{\Phi}$

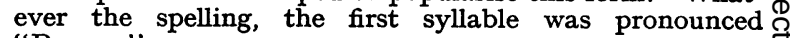


Laveran's discovery of the parasite. Manson, Ross, Grassi, and others, after years of labour, worked out the complicated development of the parasite in these insects. Then, on Manson's suggestion, a party of research workers from England lived for several months in the most unhealthy part of the Roman Campagna, among the malaria-soaked peasants. Taking no precautions against infection except that before dusk they retired to a mosquito-proof hut and stayed under cover until daylight. All remained healthy. Finally, mosquitoes fed on malaria patients in Italy were sent to London, where they were fed $\frac{\widehat{\Phi}}{\stackrel{2}{0}}$ again on volunteers who had never been abroad. $C$ These developed typical malaria, and the diagnosis $\vec{\Rightarrow}$ was clinched by the demonstration of malaria $\stackrel{\rho}{+}$ parasites in their blood. Thus the complicity of the mosquito as the vehicle of infection passed $\stackrel{\bar{F}}{\overrightarrow{2}}$ from the realm of speculation to that of established $\frac{\vec{m}}{\overrightarrow{0}}$ and proven fact.

\section{TUBERCULOUS ARTHRALGIA}

\section{By J. F. GoodwIN, M.B. M.R.C.P., LONDON}

(Some time Medical Registrar, St. Mary's Hospital, W.2; lately Physician to the Anglo-Iranian Oil $\stackrel{\hat{0}}{0}$ Company, Persia.)

Manifestations of a high degree of sensitivity to the presence of tuberculous infection within the body are usually seen shortly after the primary infection, often pulmonary, has been acquired. These manifestations occur in the immediate postprimary infective period and are an expression of a high degree of allergy which has been built up, certain parts of the body becoming highly sensitive and reacting to the tuberculous infection. Such lesions are comparable to the secondary stage of syphilis, where the whole system becomes highly sensitive to the treponema pallida, and reacts accordingly, the skin lesions being usually highly characteristic. However, in syphilis the skin lesions often contain large numbers of spirochaetes, whereas the expressions of tuberculous skin sensitivity do not contain tubercle bacilli. Other examples of this allergic state which may be cited, are serum sickness, and the syndrome complex of rheumatic fever, the latter being due to sensitisation to the Haemolytic Streptococcus. It is not generally possible to differentiate allergy from sensitivity in the case of tuberculosis.

When due to tuberculosis, these allergic reactions are to be viewed in the light of warning signals. Not in themselves of serious import, they indicate that a primary infection has occurred and that a severe post primary infection may result later unless the condition is taken seriously and complete isolation from further infection achieved. For example, a child with erythema nodosum due to a primary tuberculous infection may be dead from tuberculous meningitis within a year, although no direct evidence of any tuberculous infection other than a strongly positive Mantoux Test was present at the time.
The following allergic manifestations are usually $\stackrel{\circ}{3}$ described:

I. Erythema nodosum.

2. Pleurisy with effusion.

3. Phlyctenular conjunctivitis.

4. Rheumatism, including arthralgia.

It will be seen that these are not specific for the tubercle bacillus - erythema nodosum may and often does occur as a manifestation of acute rheumatism. Bearing in mind that poly-arthralgia and erythema nodosum may occur concurrently as reactions to either rheumatic fever or tuberculosis, it is easy to appreciate that it may be extremely difficult or even impossible to distinguish rheumatic fever from tuberculous allergy. Moreover, cardiac manifestations, other than sinus tachycardia which is often merely febrile in origin, may be absent in a child or adult suffering from rheumatic fever with florid joint manifestations, while pericarditis with effusion and pleurisy with effusion may complicate either condition. In some cases the appearance of typical rheumatic nodules and choreiform movements on the one hand; or the radiographic appearances of a primary tuberculous infection in the lungs and a strongly positive Mantoux test, on the other, may decide the issue.

The following account of a case of arthralgia complicating renal tuberculosis in an adult who gave a previous history highly suggestive of rheumatic fever, but no history suggesting primary tuberculosis, may be of interest. Tuberculous rheumatism while by no means uncommon in children 